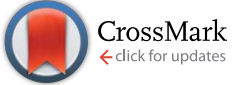

Cite this: Chem. Sci., 2016, 7, 7068

\title{
Ru-protein-Co biohybrids designed for solar hydrogen production: understanding electron transfer pathways related to photocatalytic function $\dagger$
}

\author{
Sarah R. Soltau, ${ }^{a}$ Peter D. Dahlberg, ${ }^{\text {ab }}$ Jens Niklas, ${ }^{a}$ Oleg G. Poluektov, ${ }^{a}$ \\ Karen L. Mulfort ${ }^{a}$ and Lisa M. Utschig ${ }^{\star a}$
}

A series of Ru-protein-Co biohybrids have been prepared using the electron transfer proteins ferredoxin (Fd) and flavodoxin (Fld) as scaffolds for photocatalytic hydrogen production. The light-generated charge separation within these hybrids has been monitored by transient optical and electron paramagnetic resonance spectroscopies. Two distinct electron transfer pathways are observed. The $\mathrm{Ru}-\mathrm{Fd}-\mathrm{Co}$ biohybrid produces up to 650 turnovers of $\mathrm{H}_{2}$ utilizing an oxidative quenching mechanism for $\mathrm{Ru}(\mathrm{I}) *$ and a sequential electron transfer pathway via the native [2Fe-2S] cluster to generate a $\mathrm{Ru}(\mathrm{III})-\mathrm{Fd}-\mathrm{Co}(\mathrm{I})$ charge separated state that lasts for $\sim 6 \mathrm{~ms}$. In contrast, a direct electron transfer pathway occurs for the Ru-ApoFld-Co biohybrid, which lacks an internal electron relay, generating $\mathrm{Ru}(\mathrm{I})$-ApoFld-Co(I) charge separated state that persists for $\sim 800 \mu$ s and produces 85 turnovers of $\mathrm{H}_{2}$ by a reductive quenching mechanism for Ru(II)* This work demonstrates the utility of protein architectures for linking donor and catalytic function via direct or sequential electron transfer pathways to enable stabilized charge separation which facilitates photocatalysis for solar fuel production.

Received 14th July 2016
Accepted 5th August 2016

DOI: $10.1039 / \mathrm{c} 6 \mathrm{sc} 03121 \mathrm{~h}$

www.rsc.org/chemicalscience with supramolecular, nanoparticle, or protein-based systems for proton reduction provide opportunities to directly link a PS to a catalyst to increase electron transfer efficiency. ${ }^{3}$ Supramolecular complexes for hydrogen production have proven to be quite beneficial due to their amenability to spectroscopic resolution of both ground and excited state species, ${ }^{3}$ but are often hampered by limited stability in solution ${ }^{\mathbf{4}, 5}$ or short excited state lifetimes and rapid charge recombination. ${ }^{6}$ Nanoparticle systems offer an opportunity to improve catalyst photostability and collect electrons or holes on particles until needed for catalysis. ${ }^{3}$ For example, extensive studies of the $\mathrm{RuP}^{-\mathrm{TiO}_{2}}{ }^{-}$ cobaloxime system by the Reisner group have shown the ability of nanoparticle complexes to extend charge separation lifetimes to outcompete charge recombination for high $\mathrm{H}_{2}$ production activity. $^{7-9}$

Biological platforms provide yet another approach to solar fuels generation. Metal catalysts have been inserted into synthetic or semi-synthetic proteins with the goal of creating artificial hydrogenases. ${ }^{\mathbf{1 0 , 1 1}}$ Initial efforts include covalent modification of peptides with earth abundant catalysts. ${ }^{\mathbf{1 2}}$ More recent efforts to integrate catalysts into full protein architectures include incorporation of a synthetic diiron catalyst into apo-cyt $\mathrm{c}^{\mathbf{1 3}}$ and nitrobindin $;^{14}$ insertion of cobalt porphyrins ${ }^{\mathbf{1 5 , 1 6}}$ and cobaloximes ${ }^{17}$ into apo-myoglobin; and a minimal hydrogenase model using a nickel substituted rubredoxin. ${ }^{\mathbf{1 8}}$ These protein-based systems operate similarly to multi-
${ }^{a}$ Chemical Sciences and Engineering Division, Argonne National Laboratory, Argonne, IL 60439, USA. E-mail: utschig@anl.gov; Tel: +1-630-252-3544

${ }^{b}$ Graduate Program in Biophysics, The University of Chicago, Chicago, IL 60637, USA $\dagger$ Electronic supplementary information (ESI) available: Time traces of photocatalysis, additional EPR spectra and parameters, UV-visible spectroscopy data, and kinetic fits of TA traces. See DOI: 10.1039/c6sc03121h 
molecular synthetic systems requiring diffusional interaction of catalyst and PSs (typically $\left[\mathrm{Ru}(\mathrm{bpy})_{3}\right]^{2+}$ (bpy $=2,2^{\prime}$-bipyridine) and related derivatives) and achieve up to 520 turnovers (TON) of $\mathrm{H}_{2}$ with sodium ascorbate as a sacrificial electron donor. ${ }^{19}$ To enable direct supramolecular-like charge separation, an 18amino acid peptide of cyt $\mathrm{c}_{556}$ has been modified by covalent binding of both a diiron catalyst and a $\left[\mathrm{Ru}(\mathrm{bpy})(\mathrm{tpy})\left(\mathrm{H}_{2} \mathrm{O}\right)\right]^{2+}$ (tpy $=2,2^{\prime}: 6^{\prime} 2^{\prime \prime}$-terpyridine) PS. This system achieves 9 TON with a TOF of $11 \mathrm{~h}^{-1}$ and catalysis ceases with decomposition of the diiron catalyst. ${ }^{20}$

Many recent studies directly take advantage of photosynthetic reaction center (RC) proteins optimized light capture and charge separation capabilities to drive hydrogen production from abiotic catalysts; ${ }^{21}$ yet efforts to directly link both molecular PS and catalyst to proteins are limited. Smaller protein-based systems provide a means to target essential features of the RCs within a simpler context for monitoring electron transfer kinetics and charge recombination pathways as related to catalysis. We recently designed a hybrid using directed covalent binding of a $\left[\mathrm{Ru}(\mathrm{bpy})_{3}\right]^{2+}$ derived PS ([Ru(4$\mathrm{CH}_{2} \mathrm{Br}-4^{\prime}-\mathrm{CH}_{3}-2,2^{\prime}$-bpy)(bpy $\left.)_{2}\right] \cdot 2 \mathrm{PF}_{6}$, Ru PS) and cobaloxime $\left(\mathrm{Co}\left(\mathrm{dmgBF}_{2}\right)_{2} \cdot 2 \mathrm{H}_{2} \mathrm{O}, \mathrm{CoBF}_{2}\right)$ catalyst to Spinacia oleracea ferredoxin (Fd). ${ }^{22}$ This $\mathrm{Ru}-\mathrm{Fd}-\mathrm{CoBF}_{2}$ hybrid achieves $210 \pm 60$ TON/Ru PS with $\mathrm{H}_{2}$ production for 6-8 hours. Importantly, this is the first biohybrid for which the light-induced intermediates have been spectroscopically analysed. We demonstrated evidence by electron paramagnetic resonance (EPR) and transient optical spectroscopy for the presence of a long-lived $(>1.5 \mathrm{~ms}) \mathrm{Ru}(\mathrm{III})-\mathrm{Fd}-\mathrm{Co}(\mathrm{I})$ charge separated state and an oxidative quenching mechanism of the chromophore excited state. Significantly, the native [2Fe-2S] cluster was found to be required for $\mathrm{H}_{2}$ production, serving as an electron relay to shuttle electrons from the PS to the catalyst. Herein, we further interrogate the importance of the $[2 \mathrm{Fe}-2 \mathrm{~S}]$ cluster as an intermediate redox cofactor in the Fd system and expand upon these results to include another Ru PS-protein-catalyst system that utilizes flavodoxin (Fld) isolated from the thermophilic cyanobacteria, Synechococcus lividus. Through detailed transient optical spectroscopy and EPR studies we are able to differentiate two different mechanisms for electron transfer efficiency related to photocatalytic function in $\mathrm{Ru}$-proteincatalyst systems and suggest implications for the development of biological approaches to solar hydrogen production.

\section{Results and discussion}

Preparation and photocatalytic hydrogen production of $\mathbf{R u}-$ Fd-Co biohybrids

We have reported the photocatalytic hydrogen production for the $\mathrm{Ru}-\mathrm{Fd}-\mathrm{CoBF}_{2}$ biohybrid complex from $S$. oleracea $\mathrm{Fd}$ (Fig. 1). This complex used a cobaloxime catalyst (Fig. 1A) axially ligated to the nitrogen of Fd His90 and a Ru PS covalently bound through a substitution reaction of the brominated $\mathrm{Ru}$ PS (Fig. 1C) with Cys18. ${ }^{22}$ We now have determined the quantum efficiency for the two electron process of $\mathrm{H}_{2}$ production to be $1.0 \pm 0.3 \%$ (Table 1). This $\mathrm{H}_{2}$ production quantum efficiency value compares reasonably well to multimolecular systems with

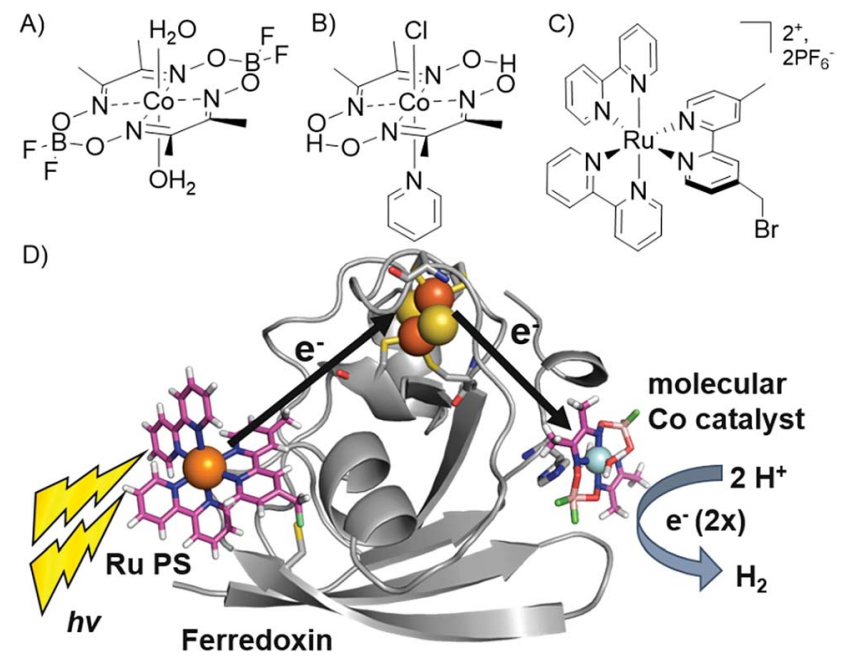

Fig. 1 ( $A-C)$ Catalysts and photosensitizers used in the current study. Cobaloxime catalysts (A) $\mathrm{Co}\left(\mathrm{dmgBF}_{2}\right)_{2} \cdot 2 \mathrm{H}_{2} \mathrm{O} \quad\left(\mathrm{CoBF}_{2}\right)$ and (B) $\mathrm{Co}(\mathrm{dmgH})_{2} \mathrm{pyCl}(\mathrm{CoPy})$ and $(\mathrm{C})$ ruthenium photosensitizer (Ru PS), $\left[\mathrm{Ru}\left(4-\mathrm{CH}_{2} \mathrm{Br}-4^{\prime}-\mathrm{CH}_{3}-2,2^{\prime}-\mathrm{bpy}\right)(\mathrm{bpy})_{2}\right] \cdot 2 \mathrm{PF}_{6}$. (D) Photocatalytic hydrogen production scheme in $\mathrm{Ru}-\mathrm{Fd}-\mathrm{CoBF}_{2}$ biohybrid utilizing electron transfer through the native $\mathrm{Fd}[2 \mathrm{Fe}-2 \mathrm{~S}]$ cluster $(1 \mathrm{~A} 70){ }^{25}$

Co polypyridy ${ }^{23}$ and Co polypyrazine ${ }^{24}$ catalysts with $\mathrm{H}_{2}$ production quantum efficiencies of $3.6 \%$ and $0.49 \%$ respectively.

In addition, we prepared another $\mathrm{Ru}-\mathrm{Fd}-\mathrm{Co}$ biohybrid complex which uses the cobaloxime catalyst $\left[\mathrm{Co}(\mathrm{dmgH})_{2}\right.$ pyridyl $]$ $\mathrm{Cl}$ (CoPy) (Fig. 1B). Previous work has suggested that the CoPy catalyst is a superior $\mathrm{H}_{2}$ evolution catalyst due to the increased lability of the pyridyl ligand allowing access for substrate binding ${ }^{26-28}$ or increased basicity of the catalyst which facilitates greater catalyst stability. ${ }^{29}$ ICP-ACS metal analysis of the Ru-FdCoPy biohybrid yielded values of $1.2 \pm 0.4 \mathrm{Co} / \mathrm{Fd}$ and $0.5 \pm 0.2$ $\mathrm{Ru} / \mathrm{Fd}$, similar to the binding ratios observed in our original $\mathrm{Ru}-$ $\mathrm{Fd}-\mathrm{CoBF}_{2}$ complex. Photocatalysis by the Ru-Fd-CoPy complex (ESI Fig. S1 $\dagger$ ) resulted in greater than triple the TOF and TON compared to that obtained with the $\mathrm{CoBF}_{2}$ complex (Table 1). This is the highest TON reported for a photocatalytic non-RC molecular PS-protein based system to date. Cobaloximes are known to be relatively unstable under common photocatalytic conditions, ${ }^{22,26}$ and incorporation of more robust hydrogen evolution catalysts, such as Co polypyridy ${ }^{23,30}$ or Ni diphosphine catalysts, ${ }^{31}$ into our protein-based hybrids could substantially improve the photocatalytic properties of these systems.

Our goal is to not only to prepare functional biohybrids, but to also understand how they work. A significant finding is that removal of the $[2 \mathrm{Fe}-2 \mathrm{~S}]$ cluster in the $\mathrm{Ru}-\mathrm{ApoFd}-\mathrm{CoBF}_{2}$ complex prevented $\mathrm{H}_{2}$ production. ${ }^{22}$ This discovery is further investigated here. In order to confirm that lack of $\mathrm{H}_{2}$ production is due to removal of the redox active [2Fe-2S] cluster and not a secondary effect of partial unfolding of the ApoFd protein, we prepared a related $\mathrm{Ru}-\mathrm{Fd}-\mathrm{Co}$ complex from $S$. oleracea $\mathrm{Fd}$ by substitution of the native $\mathrm{Fd}[2 \mathrm{Fe}-2 \mathrm{~S}]$ for $\mathrm{Ga}(\mathrm{GaFd})$. Both solution NMR and X-ray crystallographic studies demonstrate good alignment of GaFd with native Fd and the same structural fold and characterization as the native protein. ${ }^{32-34}$ Thus, 
Table 1 Photocatalysis parameters of Ru-protein-Co biohybrids in $10 \mathrm{mM}$ MES buffer, pH 6.3 with 100 mM sodium ascorbate as a sacrificial electron donor

\begin{tabular}{|c|c|c|c|}
\hline System & $\mathrm{TOF}\left[\mathrm{mol} \mathrm{H}{ }_{2}(\mathrm{~mol} \mathrm{PS})^{-1} \mathrm{~h}^{-1}\right]$ & $\operatorname{TON}^{a}\left[\mathrm{~mol} \mathrm{H}_{2}(\mathrm{~mol} \mathrm{PS})^{-1}\right]$ & $\mathrm{H}_{2}$ prod. $\mathrm{QE}$ \\
\hline $\mathrm{Ru}-\mathrm{Fd}-\mathrm{CoBF}_{2}{ }^{b}$ & $50 \pm 10$ & $210 \pm 60$ & $1.0 \pm 0.3 \%$ \\
\hline $\mathrm{Ru}-\mathrm{ApoFd}-\mathrm{CoBF}_{2}{ }^{b}$ & $0^{c}$ & $0^{c}$ & $\mathrm{Nd}^{d}$ \\
\hline $\mathrm{Ru}-\mathrm{Fd}-\mathrm{CoPy}$ & $170 \pm 10$ & $650 \pm 150$ & $\mathrm{Nd}^{d}$ \\
\hline $\mathrm{Ru}-\mathrm{ApoFld}-\mathrm{CoBF}_{2}$ & $30 \pm 10$ & $85 \pm 35$ & $0.4 \pm 0.1 \%$ \\
\hline
\end{tabular}

${ }^{a}$ TON determined after 6 h. ${ }^{b}$ Ref. 22. ${ }^{c}$ No measureable $\mathrm{H}_{2}$ detected in GC traces. ${ }^{d}$ Not determined.

replacement of the native $[2 \mathrm{Fe}-2 \mathrm{~S}]$ with Ga makes $\mathrm{Fd}$ a redox inactive protein and is therefore a useful structural model for native $\mathrm{Fd}$. After binding the $\mathrm{CoBF}_{2}$ catalyst and $\mathrm{Ru} \mathrm{PS}$, we determined metal-to-protein ratios of $1.4 \mathrm{Co} / \mathrm{Fd}$ and $0.3 \mathrm{Ru} / \mathrm{Fd}$ by ICP-AES for the Ru-GaFd-Co complex, which are consistent with the previous metal-to-protein ratios obtained for $\mathrm{Ru}-\mathrm{Fd}-$ $\mathrm{CoBF}_{2}$ and $\mathrm{Ru}-\mathrm{ApoFd}-\mathrm{CoBF}_{2}$ samples. ${ }^{22}$

Replacement of the [2Fe-2S] cofactor with Ga yields a $\mathrm{Ru}-$ GaFd-Co hybrid with no measurable light-induced $\mathrm{H}_{2}$ production (Table 1), emphasizing the importance of the [2Fe-2S] cluster for photocatalysis. In the $\mathrm{Ru}-\mathrm{Fd}-\mathrm{CoBF}_{2}$ photocatalysis scheme (Fig. 2A), based on the crystal structure of S. oleracea Fd $(1 \mathrm{~A} 70),{ }^{25}$ the distance between the Cys18 where the $\mathrm{Ru}$ PS attaches and the His 90 where the Co catalyst binds is $16.3 \AA$, whereas the distance between the Cys18 and [2Fe-2S] is $14.9 \AA$. Our null photocatalysis results for both $\mathrm{Ru}-\mathrm{ApoFd}-\mathrm{CoBF}_{2}{ }^{22}$ and $\mathrm{Ru}-\mathrm{GaFd}-\mathrm{CoBF}_{2}$ suggest that the physical distance between the catalyst and PS is too far for efficient direct electron transfer across the protein, and two electrons must travel this distance sequentially to achieve hydrogen production. Given the equivalent reduction potentials $(-0.42 \mathrm{~V} v s$. NHE) of the $\mathrm{Fd}[2 \mathrm{Fe}-2 \mathrm{~S}]$ cluster $^{35}$ and the $\mathrm{CoBF}_{2}$ catalyst, ${ }^{22}$ we expect similar driving force for the electron transfer process for each pathway. Based on a simplified picture, in which the rate of electron transfer process is primarily dependent on the distance between the donor and acceptor molecules, we estimate an $\sim 5$ fold faster rate of electron transfer between $\mathrm{Ru}-[2 \mathrm{Fe}-2 \mathrm{~S}]$ than $\mathrm{Ru}-\mathrm{Co},{ }^{36}$ although this does not take into account the edge-to-edge distances of the cofactors. We also note that electron transfer
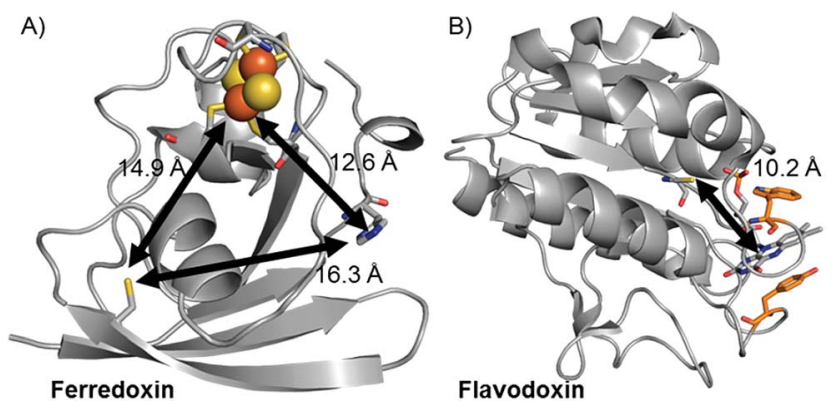

Fig. 2 Crystal structures of (A) Fd (1A70) $)^{25}$ and (B) Fld (1CZL) ${ }^{42}$ proteins with distances between possible binding sites for catalysts, PSS, and native redox cofactors. The closest relative distances between catalyst and PS binding sites and redox cofactors are indicated on the figure. rates vary in $\alpha$-helical and $\beta$-sheet proteins, and that the protein matrix may have an important role in determining the electron transfer rates between the different cofactors. $^{37-40}$ We next examine a new biohybrid for which only a direct electron transfer pathway exists for photocatalysis.

\section{Preparation and photocatalytic hydrogen production of Ru- ApoFld-Co biohybrids}

We have used S. lividus ApoFld as a scaffold to make a comparable complex to the Ru-Fd-Co biohybrids. After the native flavin mononucleotide (FMN) cofactor was extracted from Fld, the $\mathrm{CoBF}_{2}$ catalyst was reconstituted with the protein during the refolding process; a method that was developed for incorporation of a nickel diphosphine catalyst. ${ }^{41}$ Subsequent covalent modification of Cys54 of ApoFld- $\mathrm{CoBF}_{2}$ with the $\mathrm{Ru}$ PS produces the $\mathrm{Ru}$-ApoFld-CoBF${ }_{2}$ biohybrid complex. ICP-AES measurements indicate binding of $0.9 \pm 0.2 \mathrm{Co} / \mathrm{Fld}$ and $1.1 \pm$ $0.4 \mathrm{Ru} / \mathrm{Fld}$. We believe that the Co catalyst molecule is noncovalently bound within the FMN binding pocket as binding during the refolding process is necessary; with minimal binding observed to native Fld or already refolded ApoFld $(<0.15 \mathrm{Co} / \mathrm{Fld})$. Competition experiments with the native FMN cofactor support this reasoning, as overnight incubation of ApoFld-CoBF 2 with excess FMN cofactor (100 equivalents) removes up to $70 \%$ of the Co catalyst. Also note, Fld has no His residues to support axial binding of the Co catalyst. Specificity of the Ru PS binding was confirmed by 5,5'-dithio-bis(2-nitrobenzoic acid) (DTNB) modification of Cys54 preventing subsequent Ru PS binding $(<0.2 \mathrm{Ru} /$ DTNB-Fld).

The published crystal structure of Fld from $S$. elongatus (1CZL) ${ }^{42}$ which has $69 \%$ sequence identity to $S$. lividus Fld, suggests that the Ru PS binding site at Cys54 (a conserved residue) in Fld is located $10.2 \AA$ from the Co catalyst binding site in the FMN pocket (distance between the Cys thiol and the FMN N3, Fig. 2B). The Ru-ApoFld-CoBF 2 biohybrid complex provides a much shorter pathway for electron transfer (Fig. 3) as compared to the direct electron transfer pathway in the Ru-FdCo biohybrids where Ru and Co are separated by $16.3 \AA$. Estimation of the rates of electron transfer based on distance suggest an $\sim 3000$ fold faster rate for Ru-Co ET in Fld $v s$. Ru-Co ET in Fd assuming similar conditions in the protein environment. ${ }^{36}$ This is a high estimate of rate, as the edge-to-edge distances of the cofactors are not known, and ongoing crystallization experiments aim to address this issue. As with the 


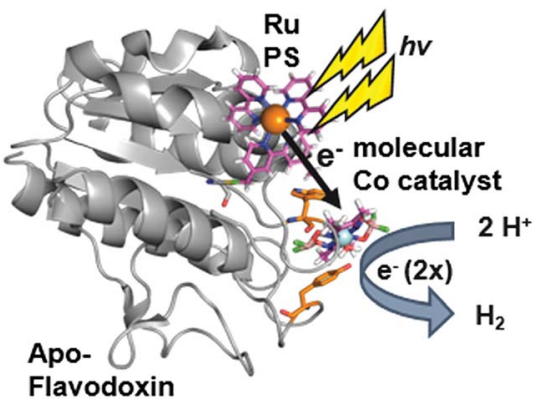

Fig. 3 Scheme for hydrogen production in Ru-ApoFld-Co biohybrid complexes with electron transfer directly from the Ru PS to the Co catalyst (1CZL). ${ }^{42}$ The protein is proposed to refold around the catalyst in the FMN binding pocket.

$\mathrm{Ru}-\mathrm{Fd}-\mathrm{CoBF}_{2}$ electron transfer rates, this rate is subject to the nature of the protein environment, and the distribution of coil, sheet, and helical structures. ${ }^{\mathbf{3 8 , 4 0}}$ Since there is no additional electron acceptor in the ApoFld system, the electron transfer pathway must be direct from Ru PS to Co for catalysis to occur.

Photocatalysis using $\mathrm{Ru}-\mathrm{ApoFld}-\mathrm{CoBF}_{2}$ complexes in MES buffer, pH 6.3 with $100 \mathrm{mM}$ sodium ascorbate produced $85 \pm 35$ TON (Table 1, ESI Fig. S1 $\dagger$ ). Turnover and $\mathrm{H}_{2}$ production quantum efficiency of $\mathrm{Ru}-\mathrm{ApoFld}-\mathrm{CoBF}_{2}$ was about $40 \%$ of $\mathrm{Ru}-$ $\mathrm{Fd}-\mathrm{CoBF}_{2}$. We hypothesize that the differences in rate and quantum efficiency for catalysis correlate to (1) the absence of the $[2 \mathrm{Fe}-2 \mathrm{~S}]$ cluster as an electron relay and/or (2) shorter distance between the cofactors; both of which might enable faster, more efficient back charge recombination. Comparison of the Fd and ApoFld biohybrids emphasize that tuning the spatial arrangement and physical distances of the electron transfer moieties can regulate photocatalysis, as has been long reported for electron transfer in Ru modified proteins. ${ }^{43}$

\section{Electron paramagnetic resonance}

EPR spectroscopy has been previously used to characterize the $\mathrm{Co}, \mathrm{Ru}$, and $[2 \mathrm{Fe}-2 \mathrm{~S}]$ cluster binding sites and probe electron transfer pathways in the $\mathrm{Ru}-\mathrm{Fd}-\mathrm{CoBF}_{2}$ biohybrid. ${ }^{22}$ The $\mathrm{CoBF}_{2}$ catalyst binds axially with single nitrogen coordination to the protein as determined by the hyperfine coupling. ${ }^{22,44}$ We also observed light-driven electron transfer from the Ru PS to the $\mathrm{CoBF}_{2}$ catalyst via a Ru(III) intermediate detected by EPR. ${ }^{22} \mathrm{We}$ have characterized the new Ru-Fd-CoPy biohybrid by EPR spectroscopy (ESI Fig. S2†) and find that this complex demonstrates a Ru(III) species upon illumination. This is consistent with our previous work with $\mathrm{Ru}-\mathrm{Fd}-\mathrm{CoBF}_{2}$ in which we proposed that oxidative quenching of $\mathrm{Ru}^{*}$ is the dominant mechanism for electron transfer between Ru PS and [2Fe-2S]. ${ }^{22}$

We have also used EPR to characterize the Co binding pocket of the Ru-ApoFld-CoBF 2 biohybrid (Fig. 4 and ESI Fig. S3†). In the absence of reductant, minimal Co(II) signal was observed (ESI Fig. S3 $\dagger$ ), which is consistent with prior reports of a mix of $\mathrm{Co}$ (II) and $\mathrm{Co}$ (III) for the resting $\mathrm{CoBF}_{2}$ catalyst when embedded in a protein environment. ${ }^{17,22}$ In the presence of excess sodium ascorbate a significant Co(II) signal was observed (Fig. 4, black).

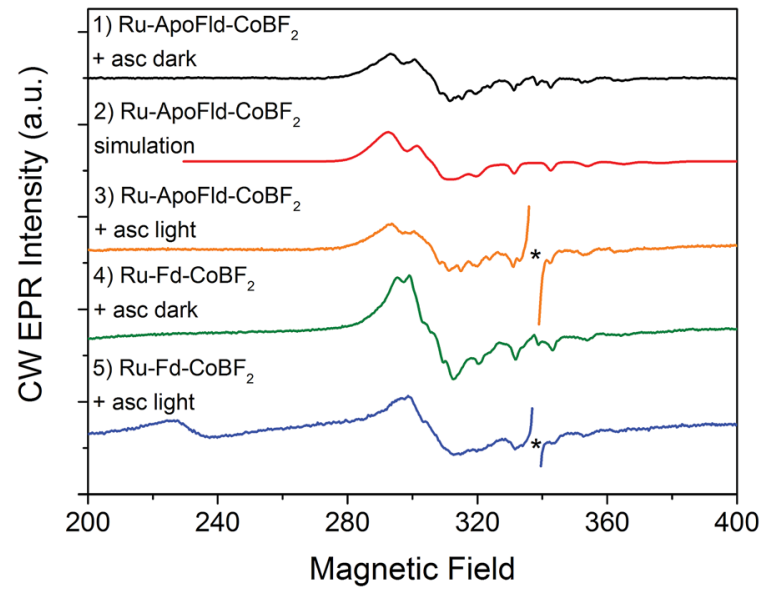

Fig. $4 \mathrm{CW}$ X-band EPR spectra of Ru-Fd-Co and Ru-ApoFld-Co biohybrids. All EPR spectra were collected at $10 \mathrm{~K}$. Samples were illuminated for $2 \mathrm{~s}$ at $293 \mathrm{~K}$, followed by immersion in liquid $\mathrm{N}_{2}$ while illuminated and placed in a pre-cooled (10 K) EPR cavity for measurement. An asterisk marks organic species omitted for clarity. $\mathrm{Ru}-\mathrm{ApoFld}-\mathrm{CoBF}_{2}+$ asc dark (black, 1); simulation of Ru-ApoFld$\mathrm{CoBF}_{2}$ (red, 2); Ru-ApoFld-CoBF $2+$ asc, light (orange, 3); $\mathrm{Ru}-\mathrm{Fd}-$ $\mathrm{CoBF}_{2}+$ asc, dark (green, 4); $\mathrm{Ru}-\mathrm{Fd}-\mathrm{CoBF}_{2}+$ asc, light (blue, 5). $\mathrm{Ru}-\mathrm{Fd}-\mathrm{CoBF}_{2}$ spectra were scaled by a factor of 0.2 for comparison to the Ru-ApoFld-CoBF 2 spectra.

The Co(II) EPR spectrum was simulated (Fig. 4, red) with $g$-value parameters $2.275,2.179$, and 2.0076 and the ${ }^{59}$ Co $A_{z}$ principal component of $318 \mathrm{MHz}$. Comparison of the spectral parameters of $\mathrm{CoBF}_{2}$ catalyst in a variety of solvent conditions suggest that the Co catalyst in $\mathrm{Ru}-\mathrm{ApoFld}-\mathrm{CoBF}_{2}$ is positioned in a polar, protic environment with two water or other oxygen atoms as axial ligands to the Co catalyst (ESI, Fig. S4 $\dagger$ ). ${ }^{44}$ The EPR results are thus consistent with the Co catalyst binding in the FMN binding pocket of ApoFld where axial ligands to the catalyst are expected to be water ligands, as there are no free nitrogen ligands (protein residues) in Fld. Additionally, these results indicate that the $\mathrm{Co}(\mathrm{II})$ in the $\mathrm{Ru}-\mathrm{ApoFld}-\mathrm{CoBF}_{2}$ and $\mathrm{Ru}-\mathrm{Fd}-$ $\mathrm{CoBF}_{2}$ (Fig. 4, green; $g_{x}, 2.250, g_{y}, 2.158, g_{z}, 2.006, A_{z} 280 \mathrm{MHz}$ ) have different coordination environments based on the $g$-value parameters, primarily due to the lack of histidine axial coordination in the ApoFld hybrid.

In these $\mathrm{Ru}-\mathrm{Co}$ hybrids, the Ru PS can transfer electrons to the catalyst via an oxidative or reductive quenching mechanism. Upon illumination of the $\mathrm{Ru}-\mathrm{Fd}-\mathrm{Co}$ hybrid with freeze trapping techniques, we observed a decrease in the Co(II) signal intensity and appearance of a $\mathrm{Ru}(\mathrm{III})$ signal consistent with oxidative quenching of $\mathrm{Ru}(\mathrm{II}) *$ by electron transfer to Co, forming an EPR silent $\mathrm{Co}(\mathrm{I})$ species (Fig. 4, blue). ${ }^{22}$ We have continued the examination of the light driven photochemistry for the $\mathrm{Ru}-$ ApoFld-CoBF 2 biohybrid by EPR. When the sample is illuminated in the presence of sodium ascorbate (Fig. 4, orange), we observe an organic radical species likely due to the ascorbate decay products in the light. Interestingly, we do not observe formation of a $\mathrm{Ru}(\mathrm{III})$ species with the $\mathrm{Ru}-\mathrm{ApoFld}-\mathrm{CoBF}_{2}$ biohybrid, either without ascorbate (ESI Fig. S3†) or in the presence of ascorbate (Fig. 4, orange). This suggests that electron transfer 
in the $\mathrm{Ru}-\mathrm{ApoFld}-\mathrm{CoBF}_{2}$ biohybrid, likely proceeds through a $\left[\mathrm{Ru}(\mathrm{bpy})_{3}\right]^{+}$species (which is a ligand centered reduction of the Ru PS that we were unable to detect by EPR), via a reductive quenching pathway in the presence of high concentrations of ascorbate. For clarity throughout the rest of manuscript, we refer to the reductively quenched $\left[\mathrm{Ru}(\mathrm{bpy})_{3}\right]^{+}$species as $\mathrm{Ru}(\mathrm{I})$. Transient optical spectroscopy has been used to help elucidate this species and propose more detailed catalytic pathways.

\section{Transient optical spectroscopy}

Transient optical spectroscopy has previously been used to investigate the species formed upon visible light excitation of the $\mathrm{Ru} \mathrm{PS}$ in the $\mathrm{Ru}-\mathrm{Fd}-\mathrm{Co}$ biohybrids. ${ }^{22}$ Using single wavelength detection of a $\operatorname{Co}(\mathrm{I})$ species at $660 \mathrm{~nm}$, we observed a long-lived (>1.5 ms) Ru(III)-Fd-Co(I) charge separated state. ${ }^{22}$ We now present a comprehensive study of the transient states in both the Ru-Fd-Co and Ru-ApoFld-Co biohybrids using full spectral collection from $\sim 1.4$ ns to several hundred milliseconds. This has allowed us to resolve the formation and decay of $\mathrm{Ru}$ and Co related species in the catalytic cycle of the $\mathrm{Ru}-\mathrm{Fd}-\mathrm{Co}$ and $\mathrm{Ru}$-ApoFld-Co biohybrids. In both cases, the Ru PS was excited with a $460 \mathrm{~nm}$ laser pulse at $10 \mathrm{~Hz}$ and transient states were probed with a continuum fiber laser across the visible spectrum. Both biohybrids were probed in the presence of 200 $\mathrm{mM}$ sodium ascorbate with sample $\mathrm{OD}_{450} \sim 0.4-0.5$.

Upon excitation of the resting $\mathrm{Ru}(\mathrm{II})$ state in both the $\mathrm{Ru}-\mathrm{Fd}-$ $\mathrm{CoBF}_{2}$ and $\mathrm{Ru}$-ApoFld-CoBF${ }_{2}$ biohybrids there is an initial feature (50-100 ns) with broad absorption from $650-750 \mathrm{~nm}$ (Fig. 5). This feature is consistent with formation of a $\mathrm{Ru}(\mathrm{II})^{*}$ species that decays within a few hundred nanoseconds. ${ }^{\mathbf{4 5 , 4 6}}$ Subsequent electron transfer forms a species with absorption centered around $510 \mathrm{~nm}$ and can be attributed to different electron transfer components in the pathways in each of the $\mathrm{Ru}$-protein-Co systems. In the $\mathrm{Ru}-\mathrm{ApoFld}-\mathrm{CoBF}_{2}$ biohybrid, electron transfer occurs via a direct pathway between Ru PS and
A)

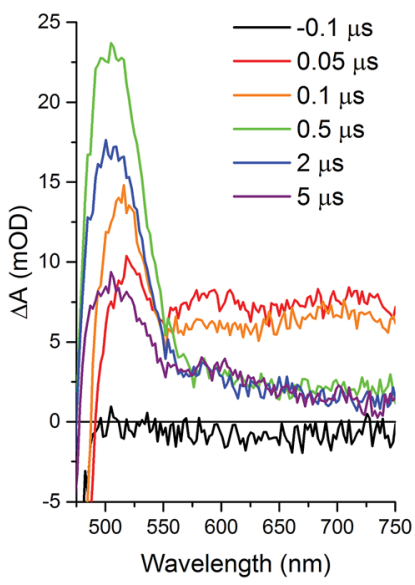

B)

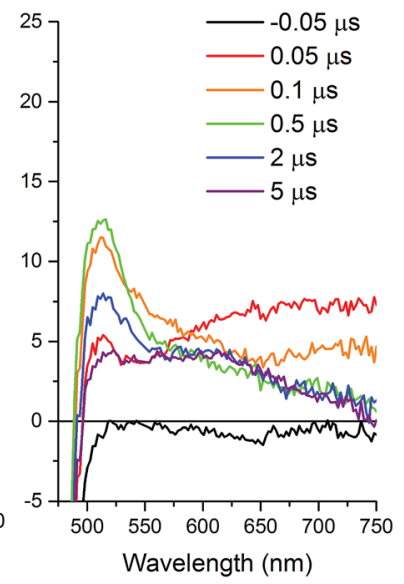

Fig. 5 Transient optical absorption spectra at selected early times. Samples contained $200 \mathrm{mM}$ sodium ascorbate and were excited at $460 \mathrm{~nm}$ and detected with a fiber laser. (A) Ru-ApoFld-CoBF 2 spectra, (B) Ru-Fd-CoBF 2 spectra.
$\mathrm{CoBF}_{2}$. We propose that the signal at $510 \mathrm{~nm}$ with $\sim 22 \mathrm{mOD}$ intensity occurs due to $\mathrm{Ru}(\mathrm{I})$, generated by reductive quenching of the excited state $\mathrm{Ru}(\mathrm{II})^{*}$ with ascorbate (eqn (1)) ${ }^{47}$

$$
\mathrm{Ru}(\mathrm{II})^{*}-\mathrm{Co}(\mathrm{II})+\mathrm{Asc} \leftrightarrows \mathrm{Ru}(\mathrm{I})-\mathrm{Co}(\mathrm{II})+\mathrm{Asc}^{+}
$$

In the case of the $\mathrm{Ru}-\mathrm{Fd}-\mathrm{CoBF}_{2}$ biohybrid, we have a more complicated situation with multiple electron transfer processes occurring on similar time scales. The native [2Fe-2S] cluster acts as an electron relay between $\mathrm{Ru}$ PS and $\mathrm{CoBF}_{2}$, which supports the formation of a Ru(III) species that we observed by EPR. ${ }^{22}$ There is also formation of a Ru(I) species due to reductive quenching with ascorbate, however, the overall intensity of the $510 \mathrm{~nm}$ feature is considerably weaker ( $13 \mathrm{mOD})$. This feature also includes a broadening with a shoulder extending to $\sim 600$ $\mathrm{nm}$ that can be observed in the $0.1-5 \mu$ s time traces for $\mathrm{Ru}-\mathrm{Fd}-$ $\mathrm{CoBF}_{2}$ (Fig. 5B) which is not observed in the time traces of the $\mathrm{Ru}$-ApoFld-CoBF 2 sample. The lower intensity of the $510 \mathrm{~nm}$ feature and shoulder broadening is consistent with some additional electron transfer intermediates which cannot be uniquely observed in $\mathrm{Ru}-\mathrm{Fd}-\mathrm{CoBF}_{2}$ due to the overlapping spectral features of the [2Fe-2S] cluster in Fd (ESI Fig. S5 $\dagger$ ). We have also characterized the electron transfer process in the $\mathrm{Ru}-$ Fd hybrid (no Co catalyst) in the ESI (Fig. S6-S8†). We therefore propose that either of the following reactions (eqn (2) and (3)) are possible in $\mathrm{Ru}-\mathrm{Fd}-\mathrm{CoBF}_{2}$, but assert that the primary pathway for catalysis uses the second reaction (eqn (3)), an oxidative quenching pathway as supported by the Ru(III) species observed by EPR.

$$
\begin{aligned}
& \mathrm{Ru}(\mathrm{II})^{*-}[2 \mathrm{Fe}-2 \mathrm{~S}]^{3+/ 3+}-\mathrm{Co}(\mathrm{II})+\mathrm{Asc} \leftrightarrows \\
& \mathrm{Ru}(\mathrm{I})-[2 \mathrm{Fe}-2 \mathrm{~S}]^{3+/ 3+}-\mathrm{Co}(\mathrm{II})+\mathrm{Asc}^{+} \\
& \mathrm{Ru}(\mathrm{II})^{*-[}[2 \mathrm{Fe}-2 \mathrm{~S}]^{3+/ 3+}-\mathrm{Co}(\mathrm{II}) \leftrightarrows \mathrm{Ru}(\mathrm{III})-[2 \mathrm{Fe}-2 \mathrm{~S}]^{2+/ 3+}-\mathrm{Co}(\mathrm{II})
\end{aligned}
$$

In eqn (3) one of the iron centers in the [2Fe-2S] cluster is reduced from $\mathrm{Fe}(\mathrm{III})$ to $\mathrm{Fe}(\mathrm{II})$, while the other remains $\mathrm{Fe}(\mathrm{III})$. Some spectral features of the $[2 \mathrm{Fe}-2 \mathrm{~S}]$ are observed in the visible region (500-650 $\mathrm{nm}$ ) upon chemical reduction with sodium dithionite (ESI Fig. S5 $\dagger$ ), which supports the broadening of the $510 \mathrm{~nm}$ feature by reduction of the $\mathrm{Fd}$ [2Fe-2S] cluster. This feature cannot be clearly resolved due to the overlapping spectral features.

Using a four-exponential equation, a global kinetic fit of the data at three selected wavelengths $(504,602$, and $736 \mathrm{~nm})$ could be used to fit the data for both the formation and decay of these early time and later time features in both biohybrids (Table 2 and Fig. 6). The observed time constant for the initial electron transfer in Ru-ApoFld-CoBF $2\left(\tau_{1}=170 \pm 30 \mathrm{~ns}\right)$ is similar to what we observed previously in Ru-ApoFd $(\tau=200 \pm 10 \mathrm{~ns}){ }^{22}$ which also lacks an internal electron acceptor and we presume proceeds through a $\mathrm{Ru}(\mathrm{I})$ intermediate as in eqn (1). By contrast, the observed time constant for initial electron transfer in Ru-Fd$\mathrm{CoBF}_{2}$ is more rapid ( $\tau_{1}=90 \pm 20 \mathrm{~ns}$ ), which is consistent with $\mathrm{Ru}(\mathrm{II})^{*} \rightarrow \mathrm{Ru}(\mathrm{III})$ electron transfer to the [2Fe-2S] cluster out competing the diffusionally governed $\mathrm{Ru}(\mathrm{II}) * \rightarrow \mathrm{Ru}(\mathrm{I})$ reductive 
Table 2 Kinetic parameters derived from transient optical spectra of $\mathrm{Ru}-\mathrm{Fd}-\mathrm{CoBF}_{2}$ and $\mathrm{Ru}-\mathrm{ApoFld}-\mathrm{CoBF}_{2}$ biohybrids in $20 \mathrm{mM} \mathrm{Hepes} \mathrm{pH}$ 7.9 with $200 \mathrm{mM}$ sodium ascorbate. Samples were excited at $460 \mathrm{~nm}$, and detected across the visible spectrum (Fig. 5 and 7). Kinetic parameters were calculated from global fits of data at 504, 602 and $736 \mathrm{~nm}$ (Fig. 6)

\begin{tabular}{lll}
\hline & Ru-Fd-CoBF & Ru-ApoFld-CoBF \\
\hline$\tau_{1}$ & $90 \pm 20 \mathrm{~ns}$ & $170 \pm 30 \mathrm{~ns}$ \\
$\tau_{2}$ & $1.5 \pm 0.3 \mu \mathrm{s}$ & $2.5 \pm 0.1 \mu \mathrm{s}$ \\
$\tau_{3}$ & $6.3 \pm 0.2 \mathrm{~ms}$ & $810 \pm 50 \mu \mathrm{s}$ \\
$\tau_{4}$ & $40 \pm 4.0 \mathrm{~ms}$ & $23 \pm 2.9 \mathrm{~ms}$ \\
\hline
\end{tabular}

A)

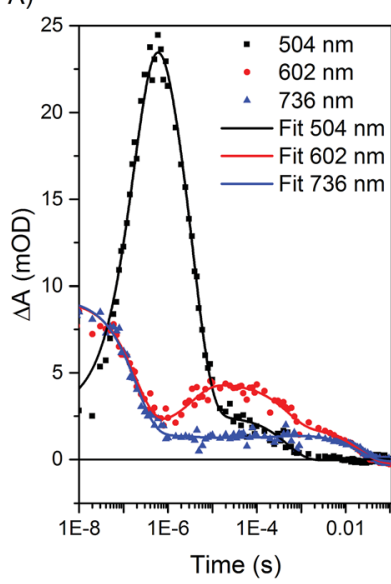

B)

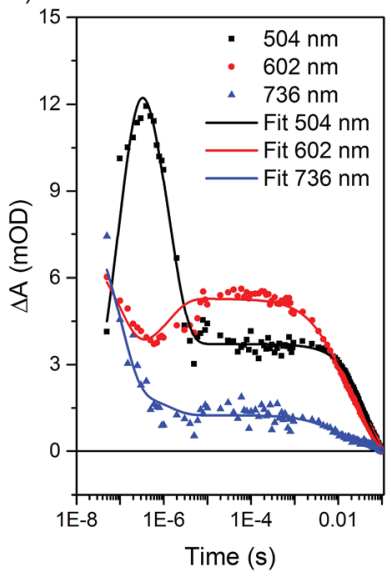

Fig. 6 Kinetic fits of transient optical kinetic data for the (A) RuApoFld- $-\mathrm{CoBF}_{2}$ and (B) Ru-Fd-CoBF 2 biohybrids with $200 \mathrm{mM}$ sodium ascorbate using a global kinetic fitting routine at three wavelengths (504 nm (black), $602 \mathrm{~nm}$ (red), and $736 \mathrm{~nm}$ (blue)) in Origin Pro 9.1. The data sets were fit with four-exponential decay functions from 10-50 ns to $100 \mathrm{~ms}$.

electron transfer. The Ru-Fd biohybrid (no Co) with ascorbate also performs initial electron transfer on a similar time scale $\left(\tau_{1}=140 \pm 10\right.$ ns, ESI Fig. S6-S8 $\left.\dagger\right)$ and is representative of the reductive quenching rate.

The species at $510 \mathrm{~nm}$ decays more slowly for Ru-ApoFld$\mathrm{CoBF}_{2}$ than for $\mathrm{Ru}-\mathrm{Fd}-\mathrm{CoBF}_{2}$ (Table 2). In the Ru-ApoFld$\mathrm{CoBF}_{2}$ biohybrid, there is only one possible pathway for $\mathrm{Ru}(\mathrm{II})^{*}$ $\rightarrow$ Co(II) electron transfer; wherein the reductively quenched $\mathrm{Ru}(\mathrm{I})$ state transfers electrons to the Co(II) catalyst, forming a Ru(II)-ApoFld-Co(I) charge separated state (eqn (4)) in $\tau_{2}=$ $2.5 \pm 0.1 \mu \mathrm{s}$.

$$
\mathrm{Ru}(\mathrm{I})-\mathrm{Co}(\mathrm{II}) \leftrightarrows \mathrm{Ru}(\mathrm{II})-\mathrm{Co}(\mathrm{I})
$$

In $\mathrm{Ru}-\mathrm{Fd}-\mathrm{CoBF}_{2}$, we propose that the primary pathway for electron transfer is from the reduced $[2 \mathrm{Fe}-2 \mathrm{~S}]^{2+/ 3+}$ cluster to the Co catalyst (eqn (5))

$$
\mathrm{Ru}(\mathrm{III})-[2 \mathrm{Fe}-2 \mathrm{~S}]^{2+/ 3+}-\mathrm{Co}(\mathrm{II}) \leftrightarrows \mathrm{Ru}(\mathrm{III})-[2 \mathrm{Fe}-2 \mathrm{~S}]^{3+/ 3+}-\mathrm{Co}(\mathrm{I})
$$

We also may observe the decay of the reductively quenched $\mathrm{Ru}(\mathrm{I})$ species with electron transfer through the $[2 \mathrm{Fe}-2 \mathrm{~S}]\left(\tau_{2}=\right.$ $1.5 \pm 0.3 \mu \mathrm{s})($ eqn $(6))$

$$
\mathrm{Ru}(\mathrm{I})-[2 \mathrm{Fe}-2 \mathrm{~S}]^{3+/ 3+}-\mathrm{Co}(\mathrm{II}) \leftrightarrows \mathrm{Ru}(\mathrm{II})-[2 \mathrm{Fe}-2 \mathrm{~S}]^{2+/ 3+}-\mathrm{Co}(\mathrm{II})
$$

Direct reduction of the [2Fe-2S] cluster in the absence of Co was observed by EPR in Ru-Fd-CoPy (ESI Fig. S2 $\dagger$ ) and Ru-Fd ${ }^{22}$ and transient optical experiments in Ru-Fd (ESI Fig. S6 $\dagger$ ), which further emphasizes the key role of the [2Fe-2S] in shuttling electrons and preventing back recombination in these biohybrids.

Longer time scale transient optical spectra show formation of an intermediate with an absorbance maximum at about 610 $\mathrm{nm}$ for both the $\mathrm{Ru}-\mathrm{Fd}-\mathrm{CoBF}_{2}$ and $\mathrm{Ru}-\mathrm{ApoFld}-\mathrm{CoBF}_{2}$ biohybrids (Fig. 7), which we attribute to the formation of a $\mathrm{Co}(\mathrm{I})$ species, an expected intermediate for $\mathrm{H}_{2}$ production by cobaloximes (ESI Fig. 9†). ${ }^{1}$ In the $\mathrm{Ru}-\mathrm{ApoFld}-\mathrm{CoBF}_{2}$ biohybrid, the $\mathrm{Ru}(\mathrm{II})-\mathrm{Co}(\mathrm{I})$ charge separated state (eqn (4)) forms in $2.5 \mu \mathrm{s}\left(\tau_{2}\right)$ and reaches maximum intensity in $<10 \mu \mathrm{s}$. In $\mathrm{Ru}-\mathrm{Fd}-\mathrm{CoBF}_{2}$, further electron transfer from intermediates proposed in eqn (3), results in formation of the charge separated species $\mathrm{Ru}(\mathrm{III})-$ Fd-Co(I) according to eqn (5). This species begins to form in $1.5 \mu \mathrm{s}\left(\tau_{2}\right)$, and reaches maximal intensity in about 10-20 $\mu \mathrm{s}$ (Fig. 7B). A Ru(II)-Fd-Co(I) intermediate could also be achieved by a reductive quenching pathway (eqn (7)).

$$
\mathrm{Ru}(\mathrm{II})-[2 \mathrm{Fe}-2 \mathrm{~S}]^{2+/ 3+}-\mathrm{Co}(\mathrm{II}) \leftrightarrows \mathrm{Ru}(\mathrm{II})-[2 \mathrm{Fe}-2 \mathrm{~S}]^{3+/ 3+}-\mathrm{Co}(\mathrm{I})
$$

This reductive pathway certainly is a viable pathway, but since we observe Ru(III) by EPR, we think that this is a minor contribution in $\mathrm{Ru}-\mathrm{Fd}-\mathrm{CoBF}_{2}$ system. The $\mu$ s time constants for formation of the $\mathrm{Co}(\mathrm{I})$ species in both biohybrids are similar to what has been observed in the literature for $\mathrm{Co}(\mathrm{I})$ species in multimolecular systems with Ru and Re PS. ${ }^{30,48,49}$
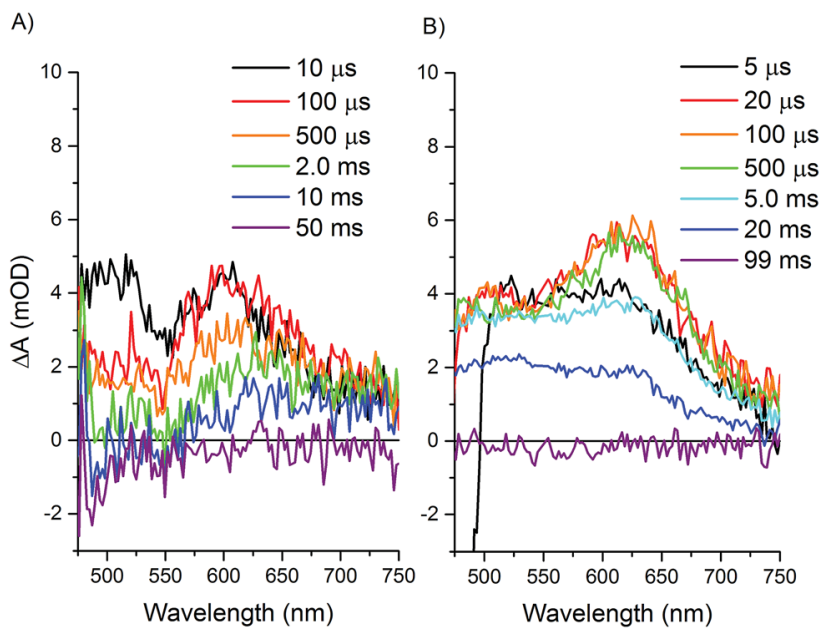

Fig. 7 Transient optical absorption spectra at selected later times. Samples contained $200 \mathrm{mM}$ sodium ascorbate and were excited at $460 \mathrm{~nm}$ and detected with a fiber laser. (A) Ru-ApoFld-CoBF 2 spectra, (B) $\mathrm{Ru}-\mathrm{Fd}-\mathrm{CoBF}_{2}$ spectra. 
The lifetimes of the charge separated states vary based on the protein environment. In $\mathrm{Ru}-\mathrm{ApoFld}-\mathrm{CoBF}_{2}$, for which we propose a direct ET pathway from electron donor to acceptor, the lifetime is $\tau_{3}=810 \pm 50 \mu$ s (Table 2). In Ru-Fd-CoBF ${ }_{2}$, for which we propose a sequential electron transfer pathway via [2Fe-2S], the lifetime is $\tau_{3}=6.3 \pm 0.2 \mathrm{~ms}$. This lifetime is consistent with our prior work in which we reported a longer than $1.5 \mathrm{~ms}$ lifetime for this charge separated state; however the previous transient absorption set up prevented data acquisition necessary to determine longer lifetimes. ${ }^{22}$

In $\mathrm{Ru}-\mathrm{Fd}-\mathrm{CoBF}_{2}$, the spectral feature at $610 \mathrm{~nm}$ for the $\mathrm{Co}(\mathrm{I})$ species decays in about $40 \mathrm{~ms}$ (Table 2), while in Ru-ApoFld$\mathrm{CoBF}_{2}$ the Co(I) species decays in about $23 \mathrm{~ms}$. These lifetimes allow full recovery of the resting $\mathrm{Co}(\mathrm{II})$ and $\mathrm{Ru}$ (II) states, but are not indicative of the time scale of $\mathrm{H}_{2}$ production. In the $\mathrm{Ru}-\mathrm{Fd}-$ $\mathrm{CoBF}_{2}$ biohybrid, $\mathrm{Ru}(\mathrm{III})$ is oxidatively quenched by sodium ascorbate to regenerate the $\mathrm{Ru}(\mathrm{II})$ resting state.

These are the first kinetic measurements for biohybrid systems, so for comparison we look to the few reported systems for Co-based synthetic systems. Axially-linked or equatoriallylinked $\mathrm{Ru}-\mathrm{Co}$ supramolecular complexes form $\mathrm{Co}(\mathrm{I})$ species that exhibit short lifetimes of 20-70 ps due to rapid charge-recombination in small synthetic architectures that cannot provide opportunities to capture or accumulate electrons needed for catalysis. ${ }^{5,6,50}$ In multimolecular systems, the $\mathrm{Co}(\mathrm{I})$ state of Copolypyridyl catalysts with Ru PSs have reported lifetimes of 30$60 \mathrm{ss}^{30,49}$ while the Co(I) state of another Co-polypyridyl complex with a Re PS has been proposed to last from 2-200 ms. ${ }^{48}$ Time-resolved X-ray absorption techniques using the $\mathrm{CoBF}_{2}$ catalyst, $\left[\mathrm{Ru}(\mathrm{bpy})_{3}\right]^{2+}$ as a PS, and methyl viologen as an electron relay show transient formation of a $\mathrm{Co}(\mathrm{I})$ species over the time regime of $0.5-100 \mu \mathrm{s},{ }^{51}$ which is consistent with the time regime for the $\mathrm{Co}(\mathrm{I})$ species in our protein hybrids.

For hydrogen generation in both $\mathrm{Ru}-\mathrm{Fd}-\mathrm{CoBF}_{2}$ and $\mathrm{Ru}-$ ApoFld- $\mathrm{CoBF}_{2}$ the $\mathrm{Co}(\mathrm{I})$ species is protonated and we propose that the mechanism of $\mathrm{H}_{2}$ catalysis proceeds through the commonly accepted hetero-coupling mechanism of cobaloximes (Scheme 1)..$^{52-54}$ It is particularly unlikely that a $\mathrm{CoBF}_{2}$ catalyst bound to a protein will diffusionally interact with another $\mathrm{Co}(\mathrm{III})-\mathrm{H}$ to proceed through the homo-coupling mechanism. ${ }^{55,56}$ Protein aggregates can be excluded as intact complexes can be observed by ICP-AES after photocatalysis or transient optical experiments with similar metal binding before and after catalysis. Thus, our experimental results favour the $\mathrm{Co}$ (III)-H scheme for catalysis, which is supported by our results with PSI-Co biohybrids ${ }^{57}$ as well as recent electrochemical studies on cobaloxime complexes. ${ }^{53,54} \mathrm{We}$ believe the addition of the second electron and proton to our system to be the rate limiting step in catalysis and further investigation of Cohydride intermediates should help to determine if this is limited by the time needed to regenerate the Ru PS.

Our protein-based hybrids serve as architectures to (1) position the PS and Co catalyst in close proximity, circumventing common diffusion-related challenges encountered by multimolecular systems and (2) stabilize long-lived (ms) chargeseparated states by way of the intermediary protein matrix which inhibits back charge recombination. We have shown that
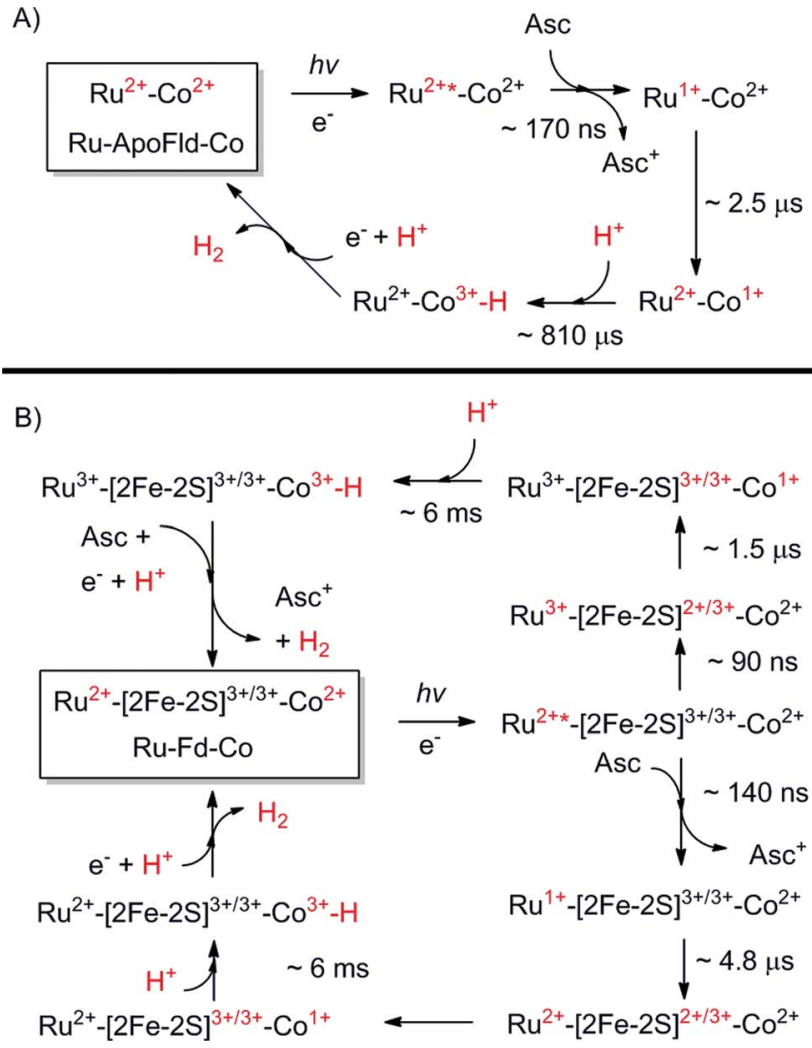

Scheme 1 Proposed catalytic cycles of both Ru-Fd-Co and RuApoFld-Co biohybrids as observed by EPR and transient optical kinetic studies. A Co(III)-H species is shown as a catalytic intermediate as discussed in the text. (A) Ru-ApoFld-Co pathway is unidirectional using a reductive quenching pathway that produces $\mathrm{H}_{2}$. (B) $\mathrm{Ru}-\mathrm{Fd}-\mathrm{Co}$ pathway is bidirectional with an oxidative quenching pathway (top) as the primary pathway to $\mathrm{H}_{2}$ production as observed by EPR. There is evidence for a small component of the reductive quenching pathway (bottom), which can continue on to perform $\mathrm{H}_{2}$ through the above scheme.

in the $\mathrm{Ru}-\mathrm{Fd}-\mathrm{CoBF}_{2}$ biohybrid, forward electron transfer is fast $(\mu \mathrm{s})$ compared to slow charge recombination (ms). This is a key feature of photosynthetic RCs which enables their stabilized charge separation: ps or ns forward electron transfers with $10^{2}$ ms lifetimes of the charge separated state. ${ }^{58}$ Additionally, the $\mathrm{Ru}-\mathrm{Fd}-\mathrm{CoBF}_{2}$ biohybrid has an [2Fe-2S] cluster that acts as an electron relay between PS and catalyst and can serve as an electron "holding place" for the second electron necessary for $\mathrm{H}_{2}$ production. Sequential electron relays are an essential design factor of the highly efficient charge separation in RC proteins. ${ }^{59}$ Thus, in combination, these RC-like features facilitate photocatalysis in our biohybrids when compared to synthetic systems.

\section{Experimental}

\section{Preparation of the Ru-protein-catalyst biohybrids}

The chemicals for the synthesis of the $\mathrm{CoBF}_{2}$, CoPy, and Ru PS were purchased from Sigma-Aldrich and used as received. The $\mathrm{CoBF}_{2}$ catalyst, ${ }^{60}$ CoPy catalyst, ${ }^{\mathbf{6 1}}$ and $\mathrm{Ru} \mathrm{PS}^{\mathbf{6 2 , 6 3}}$ were synthesized according to published methods. 
The $\mathrm{Ru}-\mathrm{Fd}-\mathrm{CoBF}_{2}$ biohybrids $(100-500 \mu \mathrm{M})$ were prepared as previously reported from $S$. oleracea Fd (Sigma-Aldrich) in 20 $\mathrm{mM}$ Hepes $\mathrm{pH} 7.9 .^{22}$ The Ru-Fd-CoPy biohybrids $(100-500 \mu \mathrm{M})$ were prepared in the same manner as the $\mathrm{Ru}-\mathrm{Fd}-\mathrm{CoBF}_{2}$ biohybrids except that a 3-5 mM stock of $\mathrm{Co}(\mathrm{dmgH})_{2}$ pyCl was used as the cobaloxime catalyst. Gallium substituted Fd (GaFd) was prepared as previously described including Q-sepharose chromatography and metal content was verified by ICP-AES. ${ }^{33} \mathrm{Ru}-$ GaFd-CoBF 2 biohybrid samples $(125 \mu \mathrm{M})$ were prepared in the same manner as the $\mathrm{Ru}-\mathrm{Fd}-\mathrm{CoBF}_{2}$ samples using GaFd instead of holo-Fd. Ru-Fd biohybrids were also prepared as previously described. ${ }^{22}$

$\mathrm{Ru}$-ApoFld-CoBF 2 biohybrids were prepared from $S$. lividus Fld purified according to published methods. ${ }^{64}$ The FNM cofactor was removed from Fld as reported previously by a trichloroacetic acid precipitation in the presence of dithiothreitol $^{41}$ and reconstitution with the $\mathrm{CoBF}_{2}$ catalyst at a final concentration of $80 \mu \mathrm{M}$ in $10 \mathrm{mM}$ Hepes $\mathrm{pH}$ 8.0. ApoFld and $\mathrm{CoBF}_{2}$ catalyst were tumbled in the dark at room temperature for $2 \mathrm{~h}$. Unbound catalyst was removed by microfiltration through 3000 MWCO centrifuge devices (Amicon Ultra) using 10 $\mathrm{mM}$ Hepes $\mathrm{pH} 8.0$ and multiple wash sequences. Ru PS binding to the ApoFld-CoBF 2 complexes was performed by adding $4 \mathrm{~mol}$ equiv. of Ru/Fld (6.5 mM stock in DMSO) in $10 \mathrm{mM}$ Hepes $\mathrm{pH}$ 8.0. The sample was tumbled at $4{ }^{\circ} \mathrm{C}$ overnight in the dark. Unbound Ru PS was removed by microfiltration using $10 \mathrm{mM}$ Hepes $\mathrm{pH}$ 8.0. ICP-AES analysis was used to determine the metal-to-protein ratios.

For competition experiments, 8-30 $\mu \mathrm{M} \mathrm{Ru-ApoFld-CoBF}{ }_{2}$ biohybrid was incubated with $100 \mathrm{~mol}$ eq. of FMN (Riboflavin 5'-monophosphate, sodium salt, Sigma Aldrich) diluted from a $5 \mathrm{mM}$ stock in $20 \mathrm{mM}$ Hepes buffer $\mathrm{pH}$ 7.3. After overnight incubation at $4{ }^{\circ} \mathrm{C}$, unbound metal ions and FMN were removed by microfiltration until all excess FMN was removed as monitored by UV-Vis. ICP-AES was used to quantitate metal binding after the competition experiment, and Co content dropped to $\sim 30 \%$. The $\mathrm{CoBF}_{2}$ catalyst (12 mol equiv. per Fld) was incubated overnight with holo-Fld (FMN bound), then washed 6 times by microfiltration to remove unbound metals or FMN cofactor. Co binding was determined by ICP-AES ( $\sim 0.15$ Co/Fld). 5,5'-Dithiobis(2-nitrobenzoic acid) (DTNB) was used to quantify free cysteine residues in Fld hybrids using the concentration of 2nitro-5-thiobenzoate anion $\left(\varepsilon_{412}=14150 \mathrm{M}^{-1} \mathrm{~cm}^{-1}\right) .{ }^{65}$ Metal content of all samples was analysed by ICP-AES on a ThermoScientific iCAP6000 spectrometer and compared to known standards. Fd and Fld protein content was determined using the Bradford protein assay method. ${ }^{66}$ In addition, holo Fd content was verified with an extinction coefficient of $9600 \mathrm{M}^{-1}$ $\mathrm{cm}^{-1}$ at $422 \mathrm{~nm},{ }^{67}$ and Fld with an extinction coefficient of $8300 \mathrm{M}^{-1} \mathrm{~cm}^{-1}$ at $465 \mathrm{~nm}^{64}$

\section{Photocatalytic hydrogen generation}

Photocatalytic hydrogen generation experiments for total TON or TOF were performed with a $300 \mathrm{~W}$ Xe lamp (Perkin-Elmer) using a long-pass $375 \mathrm{~nm}$ filter, a $29 \mathrm{~cm}$ water filter, and a shortpass filter (KG-1, Schott) in 3.0-3.8 mL sample volumes with 1-5 $\mu \mathrm{M} \mathrm{Ru}$-protein-catalyst biohybrid as previously described for the $\mathrm{Ru}-\mathrm{Fd}-\mathrm{CoBF}_{2}$ biohybrids, ${ }^{22}$ in $10 \mathrm{mM}$ MES buffer, $\mathrm{pH} 6.3$ with $100 \mathrm{mM}$ sodium ascorbate as a sacrificial electron donor. Hydrogen was detected from headspace measurements with a Varian CP-4900A micro gas chromatograph with a $10 \mathrm{~m} 5 \AA$ molecular sieves column with a thermal conductivity detector and UHP $\mathrm{N}_{2}$ carrier gas. Calibration curves for $\mathrm{H}_{2}$ concentrations were determined using injections of a known standard of $3 \% \mathrm{H}_{2}$ in $\mathrm{N}_{2}$.

For the determination of $\mathrm{H}_{2}$ evolution quantum efficiency, a CW LED centered at $455 \mathrm{~nm}$ (ThorLabs 455L2) with a DC2100 power controller (ThorLabs) was used to estimate light illuminating the sample at $\sim 455 \mathrm{~nm}$. Higher protein concentrations (5-10 $\mu \mathrm{M})$ were required to determine quantum efficiency due to small spot size of the LED on the sample (area $=6.4 \times 10^{-5}$ $\mathrm{m}^{2}$ ). Quantum efficiency was calculated according to eqn (8).

$$
\% \mathrm{QE}=\left[\frac{2\left(\mathrm{~mol} \mathrm{H}_{2} \text { per } \mathrm{s}\right)}{\text { mol photons per } \mathrm{s}}\right][100]
$$

Hydrogen production rates $\left(\mathrm{mol} \mathrm{H}_{2}\right.$ per $\left.\mathrm{s}\right)$ were calculated from headspace measurements of gas evolution with gas chromatograph per unit time as described above. Initial photon flux at $455 \mathrm{~nm}$ was measured with a Quantum Meter (Apogee Instruments Inc.), and corrected for the spot area, with LED power decreased to $<3000 \mu \mathrm{mol}$ photons per $\mathrm{m}^{2}$ per s according to the meter and multiplied by the spot area (unit $=\mathrm{mol}$ photons per s). Photon flux on the sample during illumination was determined by UV-visible spectroscopy of the Ru bound fraction of the sample, as determined by ICP-AES, and this value was multiplied by the spot area. The change in photon flux was used to determine mol photons per s.

\section{Electron paramagnetic resonance}

Biohybrid protein ( $\mathrm{Ru}-\mathrm{Fd}-\mathrm{CoPy}, \mathrm{Ru}-\mathrm{ApoFld}-\mathrm{CoBF}_{2}$, and $\mathrm{Ru}-$ $\mathrm{Fd}-\mathrm{CoBF}_{2}$ ) samples were prepared as discussed above in $20 \mathrm{mM}$ Hepes buffer pH 7.9 at protein concentrations of $400-500 \mu \mathrm{M}$. $200 \mathrm{mM}$ sodium ascorbate was added to samples. The sample of Fd reduced with sodium dithionite was prepared with $400 \mu \mathrm{M}$ Fd in $100 \mathrm{mM}$ CAPS buffer, pH 10.0 with $10 \mathrm{mM}$ sodium dithionite. Samples were prepared in quartz EPR tubes in a nitrogen box as previously described. ${ }^{22} \mathrm{CW}$ X-band $(9 \mathrm{GHz})$ EPR experiments were performed with a Bruker ELEXSYS E580 EPR spectrometer (Bruker Biospin, Rheinstetten, Germany) equipped with a super high Q resonator (Bruker ER 4122SHQE) and a helium gas-flow cryostat (ICE Oxford, UK). Temperature control was provided by an ITC (Oxford Instruments, UK) and illumination was performed with a $300 \mathrm{~W}$ Xe lamp (PerkinElmer) using a $15 \mathrm{~cm}$ water filter, a KG-2 filter (Schott) and a 400 nm long pass filter to block UV and IR light. $200 \mathrm{~K}$ illumination was performed in a dry ice/ethanol bath directly in the light, while $293 \mathrm{~K}$ illumination was performed directly in the light without additional temperature control. Samples were illuminated for $2 \mathrm{~s}$ before immersion in liquid $\mathrm{N}_{2}$ under illumination and subsequent placement in a pre-cooled EPR cavity. Data processing was performing using Xepr (Bruker BioSpin, 
Rheinstetten, Germany) and MatlabTM 7.11.2 (MathWorks) environment. The magnetic parameters were simulated using EasySpin. ${ }^{68}$

\section{Transient optical spectroscopy}

$\mathrm{Ru}-\mathrm{Fd}, \quad \mathrm{Ru}-\mathrm{Fd}-\mathrm{CoBF}_{2}$, and Ru-ApoFld-CoBF 2 biohybrid samples were prepared as described above to $\sim 250-500 \mu \mathrm{M}$ in $20 \mathrm{mM}$ Hepes buffer, $\mathrm{pH} 7.9$ and placed in $2 \mathrm{~mm}$ cuvettes to provide sufficient optical density $\left(A_{450 \mathrm{~nm}} \sim 0.4-0.5\right)$. Nitrogen gas was bubbled over the top of samples for at least 10 minutes before collecting spectra. Aliquots of sodium ascorbate were injected to a concentration of $200 \mathrm{mM}$ in appropriate samples before excitation.

Transient absorption measurements were performed using a homebuilt instrument. The optical pump was generated using a diode pumped Nd:YAG and OPA system tuned to $460 \mathrm{~nm}$ (Ekspla PL220 and PG403). The repetition rate for the pump beam was $10 \mathrm{~Hz}$ with a pulse power of $350 \mu \mathrm{J} \mathrm{cm}^{-2}$ at the sample. The broadband probe was generated via a supercontinuum fiber laser (Leukos STM). The probe repetition rate was $1.0 \mathrm{kHz}$ and pulse power was $\sim 10 \mu \mathrm{J} \mathrm{cm}^{-2}$. The time delay between the optical pump and probe beams was obtained using a delay generator (SRS DG535) giving an overall instrument response function of $\sim 1.4 \mathrm{~ns}$ (ESI Fig. S10 $\dagger$ ). Dithering of a stir bar during data collection allowed continuous mixing of samples throughout the measurement. UV-visible spectra of the samples after the transient optical measurements were collected to check for sample degradation. Data was binned by a factor of 4 or 16 and four-exponential kinetic fits were determined by a Global Fitting routine for the three selected wavelengths (504 nm, $602 \mathrm{~nm}, 736 \mathrm{~nm}$ ) using Origin Pro 9.1 from 10$50 \mathrm{~ns}$ to $100 \mathrm{~ms}$. The specific fitting wavelengths $(504 \mathrm{~nm}$, $602 \mathrm{~nm}$, and $736 \mathrm{~nm}$ ) were selected as near the center of the $\mathrm{Ru}(\mathrm{I})$ species, Co(I) species, and Ru(II)* species, respectively, while the 504 and $602 \mathrm{~nm}$ wavelengths also represent the broadening of the $\mathrm{Ru}(\mathrm{I})$ signal from reduction of the [2Fe-2S] cluster in $\mathrm{Ru}-\mathrm{Fd}-\mathrm{Co}$. Data collection time averaged about 2 hours for each short time scale data set and an additional 2 hours for each long time scale data set.

\section{Conclusions}

We have developed two systems for photocatalytic hydrogen production that both directly link a proton reduction catalyst and a PS with a protein scaffold (Scheme 1), yet utilize different electron transfer pathways to achieve catalysis. The first system, $\mathrm{Ru}-\mathrm{Fd}-\mathrm{Co}$, uses an internal electron transfer relay through the [2Fe-2S] cluster of Fd to transport electrons to the Co catalyst using an oxidative quenching mechanism via $\mathrm{Ru}(\mathrm{III})$. Our extensive EPR and transient optical spectroscopy studies indicate that a long lived (6.3 $\pm 0.2 \mathrm{~ms})$ light-induced $\mathrm{Ru}(\mathrm{III})-\mathrm{Fd}-$ $\mathrm{Co}(\mathrm{I})$ charge separated state forms which gives this hybrid system increased stability and longevity as a photocatalytic system. We have also studied the ability to perturb and modify this system, through removal of the [2Fe-2S] cluster $^{22}$ and replacement of the $[2 \mathrm{Fe}-2 \mathrm{~S}]$ with a redox inactive metal, Ga.
Photocatalysis is not observed in the absence of the redox active cofactor, supporting our assertion that sequential electron transfer pathway thru the $[2 \mathrm{Fe}-2 \mathrm{~S}]$ cluster is the functional pathway. Changing the catalyst from the $\mathrm{CoBF}_{2}$ catalyst previously studied $^{22}$ to the CoPy catalyst increases the catalytic turnover of the system by a factor of greater than three.

The second system, Ru-ApoFld-Co, does not contain an internal electron transfer relay and we propose that lightinduced electron transfer from the Ru PS directly to the Co catalyst initiates photocatalysis. This system relies on a close spatial arrangement of electron donor and acceptor for direct transfer of electrons necessary for hydrogen production. Through our EPR and transient optical spectroscopy results, we demonstrate that the Ru-ApoFd-Co biohybrid utilizes a Ru(II)$\mathrm{Co}$ (I) charge separated state formed after reductive quenching of the Ru PS. This species has a shorter lifetime, $810 \pm 50 \mu \mathrm{s}$ which might be the result of more favorable back charge recombination due to the shorter distance between cofactors or the lack of an intermediary electron acceptor. Through these two different systems, we have developed a new regime for protein engineering to place catalysts, PSs, and redox active electron transfer moieties at designed locations in the protein scaffolds to enable rapid electron transfer and prohibit charge recombination. Continued studies of biohybrid designs will provide a knowledge base about system catalysis function related to underlying electron transfer kinetic mechanisms and pathways that will guide future development of photochemical systems for conversion and storage of sunlight.

\section{Acknowledgements}

This work is supported by the Division of Chemical Sciences, Geosciences, and Biosciences, Office of Basic Energy Sciences of the U.S. Department of Energy under Contract No. DE-AC02$06 \mathrm{CH} 11357$.

\section{Notes and references}

1 J. L. Dempsey, B. S. Brunschwig, J. R. Winkler and H. B. Gray, Acc. Chem. Res., 2009, 42, 1995-2004.

2 P. W. Du and R. Eisenberg, Energy Environ. Sci., 2012, 5, 6012-6021.

3 K. L. Mulfort and L. M. Utschig, Acc. Chem. Res., 2016, 49, 835-843.

4 A. Fihri, V. Artero, M. Razavet, C. Baffert, W. Leibl and M. Fontecave, Angew. Chem., Int. Ed., 2008, 47, 564-567.

5 K. L. Mulfort, A. Mukherjee, O. Kokhan, P. W. Du and D. M. Tiede, Chem. Soc. Rev., 2013, 42, 2215-2227.

6 A. Mukherjee, O. Kokhan, J. Huang, J. Niklas, L. X. Chen, D. M. Tiede and K. L. Mulfort, Phys. Chem. Chem. Phys., 2013, 15, 21070-21076.

7 A. Reynal, F. Lakadamyali, M. A. Gross, E. Reisner and J. R. Durrant, Energy Environ. Sci., 2013, 6, 3291-3300.

8 F. Lakadamyali and E. Reisner, Chem. Commun., 2011, 47, 1695-1697.

9 A. Reynal, E. Pastor, M. A. Gross, S. Selim, E. Reisner and J. R. Durrant, Chem. Sci., 2015, 6, 4855-4859. 
10 T. L. Olson, E. Espiritu, S. Edwardraja, C. R. Simmons, J. C. Williams, G. Ghirlanda and J. P. Allen, Biochim. Biophys. Acta, Bioenerg., 2016, 1857, 539-547.

11 B. R. Lichtenstein, C. Bialas, J. F. Cerda, B. A. Fry, P. L. Dutton and C. C. Moser, Angew. Chem., Int. Ed., 2015, 54, 13626-13629.

12 A. Roy, C. Madden and G. Ghirlanda, Chem. Commun., 2012, 48, 9816-9818.

13 Y. Sano, A. Onoda and T. Hayashi, Chem. Commun., 2011, 47, 8229-8231.

14 A. Onoda, Y. Kihara, K. Fukumoto, Y. Sano and T. Hayashi, ACS Catal., 2014, 4, 2645-2648.

15 D. J. Sommer, M. D. Vaughn and G. Ghirlanda, Chem. Commun., 2014, 50, 15852-15855.

16 D. J. Sommer, M. D. Vaughn, B. C. Clark, J. Tomlin, A. Roy and G. Ghirlanda, Biochim. Biophys. Acta, Bioenerg., 2016, 1857, 598-603.

17 M. Bacchi, G. Berggren, J. Niklas, E. Veinberg, M. W. Mara, M. L. Shelby, O. G. Poluektov, L. X. Chen, D. M. Tiede, C. Cavazza, M. J. Field, M. Fontecave and V. Artero, Inorg. Chem., 2014, 53, 8071-8082.

18 J. W. Slater and H. S. Shafaat, J. Phys. Chem. Lett., 2015, 6, 3731-3736.

19 B. Kandemir, S. Chakraborty, Y. Guo and K. L. Bren, Inorg. Chem., 2016, 55, 467-477.

20 Y. Sano, A. Onoda and T. Hayashi, J. Inorg. Biochem., 2012, 108, 159-162.

21 L. M. Utschig, S. R. Soltau and D. M. Tiede, Curr. Opin. Chem. Biol., 2015, 25, 1-8.

22 S. R. Soltau, J. Niklas, P. D. Dahlberg, O. G. Poluektov, D. M. Tiede, K. L. Mulfort and L. M. Utschig, Chem. Commun., 2015, 51, 10628-10631.

23 M. Nippe, R. S. Khnayzer, J. A. Panetier, D. Z. Zee, B. S. Olaiya, M. Head-Gordon, C. J. Chang, F. N. Castellano and J. R. Long, Chem. Sci., 2013, 4, 3934-3945.

24 J. W. Jurss, R. S. Khnayzer, J. A. Panetier, K. A. El Roz, E. M. Nichols, M. Head-Gordon, J. R. Long, F. N. Castellano and C. J. Chang, Chem. Sci., 2015, 6, 49544972.

25 C. Binda, A. Coda, A. Aliverti, G. Zanetti and A. Mattevi, Acta Crystallogr., Sect. D: Biol. Crystallogr., 1998, 54, 1353-1358.

26 T. M. McCormick, B. D. Calitree, A. Orchard, N. D. Kraut, F. V. Bright, M. R. Detty and R. Eisenberg, J. Am. Chem. Soc., 2010, 132, 15480-15483.

27 T. Lazarides, T. McCormick, P. W. Du, G. G. Luo, B. Lindley and R. Eisenberg, J. Am. Chem. Soc., 2009, 131, 9192-9194.

28 P. W. Du, J. Schneider, G. G. Luo, W. W. Brennessel and R. Eisenberg, Inorg. Chem., 2009, 48, 4952-4962.

29 A. Panagiotopoulos, K. Ladomenou, D. Sun, V. Artero and A. G. Coutsolelos, Dalton Trans., 2016, 45, 6732-6738.

30 R. S. Khnayzer, V. S. Thoi, M. Nippe, A. E. King, J. W. Jurss, K. A. El Roz, J. R. Long, C. J. Chang and F. N. Castellano, Energy Environ. Sci., 2014, 7, 1477-1488.

31 M. P. McLaughlin, T. M. McCormick, R. Eisenberg and P. L. Holland, Chem. Commun., 2011, 47, 7989-7991.

32 X. Xu, S. Scanu, J. S. Chung, M. Hirasawa, D. B. Knaff and M. Ubbink, Biochemistry, 2010, 49, 7790-7797.
33 X. Xu, S. K. Kim, P. Schurmann, M. Hirasawa, J. N. Tripathy, J. Smith, D. B. Knaff and M. Ubbink, FEBS Lett., 2006, 580, 6714-6720.

34 R. Mutoh, N. Muraki, K. Shinmura, H. Kubota-Kawai, Y. H. Lee, M. M. Nowaczyk, M. Rogner, T. Hase, T. Ikegami and G. Kurisu, Biochemistry, 2015, 54, 6052-6061.

35 R. Cammack, K. K. Rao, C. P. Bargeron, K. G. Hutson, P. W. Andrew and L. J. Rogers, Biochem. J., 1977, 168, 205209.

36 C. C. Moser, J. M. Keske, K. Warncke, R. S. Farid and P. L. Dutton, Nature, 1992, 355, 796-802.

37 A. W. Axup, M. Albin, S. L. Mayo, R. J. Crutchley and H. B. Gray, J. Am. Chem. Soc., 1988, 110, 435-439.

38 D. S. Wuttke, M. J. Bjerrum, J. R. Winkler and H. B. Gray, Science, 1992, 256, 1007-1009.

39 J. N. Onuchic, D. N. Beratan, J. R. Winkler and H. B. Gray, Annu. Rev. Biophys. Biomol. Struct., 1992, 21, 349-377.

40 M. J. Bjerrum, D. R. Casimiro, I. J. Chang, A. J. Di Bilio, H. B. Gray, M. G. Hill, R. Langen, G. A. Mines, L. K. Skov, J. R. Winkler, et al., J. Bioenerg. Biomembr., 1995, 27, 295-302. 41 S. C. Silver, J. Niklas, P. W. Du, O. G. Poluektov, D. M. Tiede and L. M. Utschig, J. Am. Chem. Soc., 2013, 135, 13246-13249.

42 D. M. Hoover, C. L. Drennan, A. L. Metzger, C. Osborne, C. H. Weber, K. A. Pattridge and M. L. Ludwig, J. Mol. Biol., 1999, 294, 725-743.

43 T. J. Meade, H. B. Gray and J. R. Winkler, J. Am. Chem. Soc., 1989, 111, 4353-4356.

44 J. Niklas, K. L. Mardis, R. R. Rakhimov, K. L. Mulfort, D. M. Tiede and O. G. Poluektov, J. Phys. Chem. B, 2012, 116, 2943-2957.

45 P. Muller and K. Brettel, Photochem. Photobiol. Sci., 2012, 11, 632-636.

46 A. N. Tarnovsky, W. Gawelda, M. Johnson, C. Bressler and M. Chergui, J. Phys. Chem. B, 2006, 110, 26497-26505.

47 B. Shan, T. Baine, X. A. N. Ma, X. Zhao and R. H. Schmehl, Inorg. Chem., 2013, 52, 4853-4859.

48 A. Rodenberg, M. Orazietti, B. Probst, C. Bachmann, R. Alberto, K. K. Baldridge and P. Hamm, Inorg. Chem., 2015, 54, 646-657.

49 A. Lewandowska-Andralojc, T. Baine, X. Zhao, J. T. Muckerman, E. Fujita and D. E. Polyansky, Inorg. Chem., 2015, 54, 4310-4321.

50 K. L. Mulfort and D. M. Tiede, J. Phys. Chem. B, 2010, 114, 14572-14581.

51 G. Smolentsev, B. Cecconi, A. Guda, M. Chavarot-Kerlidou, J. A. van Bokhoven, M. Nachtegaal and V. Artero, Chemistry, 2015, 21, 15158-15162.

52 B. H. Solis and S. Hammes-Schiffer, J. Am. Chem. Soc., 2011, 133, 19036-19039.

53 E. S. Rountree, D. J. Martin, B. D. McCarthy and J. L. Dempsey, ACS Catal., 2016, 6, 3326-3335.

54 E. S. Wiedner and R. M. Bullock, J. Am. Chem. Soc., 2016, 138, 8309-8318.

55 J. T. Muckerman and E. Fujita, Chem. Commun., 2011, 47, 12456-12458.

56 D. C. Lacy, G. M. Roberts and J. C. Peters, J. Am. Chem. Soc., 2015, 137, 4860-4864. 
57 L. M. Utschig, S. C. Silver, K. L. Mulfort and D. M. Tiede, J. Am. Chem. Soc., 2011, 133, 16334-16337.

58 R. E. Blankenship, Molecular Mechanisms of Photosynthesis, Blackwell Science Ltd, Malden, USA, 2002.

59 C. E. Lubner, R. Grimme, D. A. Bryant and J. H. Golbeck, Biochemistry, 2010, 49, 404-414.

60 A. Bakac and J. H. Espenson, J. Am. Chem. Soc., 1984, 106, 5197-5202.

61 W. C. Trogler, R. C. Stewart, L. A. Epps and L. G. Marzilli, Inorg. Chem., 1974, 13, 1564-1570.

62 L. C. Sun, H. Berglund, R. Davydov, T. Norrby, L. Hammarstrom, P. Korall, A. Borje, C. Philouze, K. Berg, A. Tran, M. Andersson, G. Stenhagen, J. Martensson,
M. Almgren, S. Styring and B. Akermark, J. Am. Chem. Soc., 1997, 119, 6996-7004.

63 S. Gould, G. F. Strouse, T. J. Meyer and B. P. Sullivan, Inorg. Chem., 1991, 30, 2942-2949.

64 H. L. Crespi, U. Smith, L. Gajda, T. Tisue and R. M. Ammeraal, Biochim. Biophys. Acta, Bioenerg., 1972, 256, 611-618.

65 P. W. Riddles, R. L. Blakeley and B. Zerner, Methods Enzymol., 1983, 91, 49-60.

66 M. M. Bradford, Anal. Biochem., 1976, 72, 248-254.

67 G. Moal and B. Lagoutte, Biochim. Biophys. Acta, Bioenerg., 2012, 1817, 1635-1645.

68 S. Stoll and A. Schweiger, J. Magn. Reson., 2006, 178, 42-55. 